\title{
The anti-Staphylococcus aureus activity of the phenanthrene fraction from fibrous roots of Bletilla striata
}

Jing-Jing Guo ${ }^{1,2}$, Bin-Ling Dai', Ni-Pi Chen, Li-Xia Jin, Fu-Sheng Jiang ${ }^{1}$, Zhi-Shan Ding ${ }^{1}$ and Chao-Dong Qian ${ }^{*}$

\begin{abstract}
Background: Bletillae Rhizoma, the tuber of Bletilla striata, has been used in Chinese traditional medicine to treat infectious diseases. Chemical studies indicated that phenanthrene was one of the most important components of the herb, with a broad spectrum of antibiotic activity against Gram-positive bacteria. The objective of this study was to further characterize the antibacterial activity of the phenanthrene fraction from the fibrous root of the pseudobulb of B. striata.

Methods: The phenanthrene fraction (EF60) from the ethanol extract of fibrous roots of Bletilla striata pseudobulbs was isolated using polyamide column chromatography. The antibacterial activity of the fraction was evaluated in vitro using a 96-well microtiter plate and microbroth dilution method. The cytotoxicity of EF60 against mammalian cells was tested by hemolysis and MTT assays.

Results: EF60 was obtained using alcohol extraction and polyamide column chromatography, with a yield of $14.9 \mathrm{~g}$ per $1 \mathrm{~kg}$ of the fibrous roots of B. striata. In vitro tests indicated that EF60 was active against all tested strains of Staphylococcus aureus, including clinical isolates and methicillin-resistant S. aureus (MRSA). The minimum inhibitory concentration (MIC) values of EF60 against these pathogens ranged from 8 to $64 \mu \mathrm{g} / \mathrm{mL}$. Minimum bactericidal concentration tests demonstrated that EF60 was bactericidal against S. aureus 3304 and ATCC 29213 and was bacteriostatic against S. aureus 3211, ATCC 25923, and ATCC 43300. Consistently, the time-kill assay indicated that EF60 could completely kill S. aureus ATCC 29213 at $2 \times$ the MIC within 3 h but could kill less than two logarithmic units of ATCC 43300, even at 4X the MIC within $24 \mathrm{~h}$. The postantibiotic effects (PAE) of EF60 (4X MIC) against strains 29213 and 43300 were 2.0 and 0.38 h, respectively. Further studies indicated that EF60 $(160 \mu \mathrm{g} / \mathrm{mL})$ showed no cytotoxicity against human erythrocytes, and was minimally toxic to Human Umbilical Vein Endothelial Cells with an $\mathrm{IC}_{50}$ of $75 \mathrm{\mu g} / \mathrm{mL}$.
\end{abstract}

Conclusions: Our studies indicated that EF60 is worthy of further investigation as a potential phytotherapeutic agent for treating infections caused by S. aureus and MRSA.

Keywords: Bletillae Rhizom, Gram-positive bacteria, Antibacterial, Time-kill assays, Postantibiotic effect

\footnotetext{
* Correspondence: gian201@163.com

'Zhejiang Chinese Medical University, Hangzhou, Zhejiang Province, China

Full list of author information is available at the end of the article
} 


\section{Background}

With the widespread use of antibiotics, antimicrobial resistance has become a major medical and public health problem [1-3]. Of particular concern is methicillinresistant Staphylococcus aureus (MRSA), which has disseminated throughout the world and is a global human health problem due to infections in both hospitals and the community $[4,5]$. Glycopeptides are the gold standard to treat MRSA infections, but vancomycin- and teicoplanin-resistant bacteria have also emerged [6-8]. There is therefore an urgent need for new strategies to treat the infections caused by antibiotic-resistant pathogens. The discovery and development of antibacterial natural products, which are becoming increasingly popular among consumers, are an alternative method for controlling these diseases $[9,10]$.

Bletillae Rhizoma, the pseudobulbs of Bletilla striata (Reichb. f.), has been used in Chinese traditional medicine to treat pneumorrhagia and pneumonophthisis [11]. It is also frequently applied for curing skin cracks, abscesses, and burns when combined with other herbal medicine. Previous investigations on the constituents of Bletillae Rhizoma have revealed the presence of monomeric phenanthrene, dimeric phenanthrenes, and their derivatives, which contain a potent antibacterial activity against Gram-positive bacteria [12-14]. It is worth noting that phenanthrenes are a rather uncommon class of aromatic metabolites that have mainly been found in the Orchidaceae family [14]. Although a large number of phenanthrenes have been isolated from Bletillae Rhizoma and have been demonstrated to possess antimicrobial activities, further pharmacological studies of these compounds are limited due to low content of phenanthrenes in the pseudobulbs of $B$. striata.

The fibrous roots of the pseudobulbs of $B$. striata are usually discarded during its processing and commercialization, which represents a waste of natural resources. Our recent study indicated that the chemical composition of fibrous roots is similar to that of $B$. striata pseudobulbs; however, the total phenolic content in the former is higher than that in the latter [15]. Further study showed that the fibrous part of B. striata is a rich source of phenanthrene compounds, and six phenanthrenes, including four new biphenanthrenes containing antibacterial activity, were isolated from a 95\% ethanol extract [16]. To date, 34 phenanthrene compounds isolated from $B$. striata have been extensively described [12-14, 16-18]. However, there was a predominant tendency to publish the isolation and activity screening of phenanthrenes in the past years. Little information is available on the antimicrobial activity more in depth of this kind of compounds, regardless of monomer or mixture. Thus, the aim of this study was to isolate and characterize further the antimicrobial phenanthrene fraction isolated from fibrous roots of $B$. striata pseudobulbs.

\section{Methods \\ Bacteria strains}

S. aureus ATCC 25923, S. aureus ATCC 29213, S. aureus ATCC 43300, E. coli ATCC 35218, and P. aeruginosa ATCC 27853 were purchased from the American Type Culture Collection. Bacillus subtilis 168 was a gift from Mei-Ya Li (Zhejiang Chinese Medical University, Hangzhou, China). Clinical isolates were obtained from patients at the Shaoxing Central Hospital, Shaoxing, China.

\section{Preparation of the phenanthrene fraction}

The rhizomes of B. striata were collected from Tuankou Town, Zhejiang Province, People's Republic of China, and authenticated by Prof. ZS Ding (one of the authors). A voucher specimen was deposited in Zhejiang Chinese Medical University with specimen number BS-2012-I. The air-dried and powdered fibrous roots $(1.0 \mathrm{~kg})$ were extracted with $15 \mathrm{~L}$ of $95 \%$ ethanol under reflux, three times (each time, $60 \mathrm{~min}$ ). The extract was concentrated under reduced pressure and yielded $94 \mathrm{~g}$ of crude ethanol extract. The ethanol extract was loaded onto a polyamide resin column and washed with distilled water, followed by elution with 20, 40, 60, 80, and 95\% (v/v) ethanol. Each fraction was collected and tested for antibacterial activity using the agar diffusion method [19]. The tests were repeated three times to ensure reliability. The active fraction (EF60) eluted with $60 \%$ ethanol in water were dried in a vacuum and analyzed using a Dionex Ultimate 3000 high-performance liquid chromatography (HPLC) System (Thermo Fisher Scientific, Waltham, USA) with a diodearray ultraviolet/visible (UV-VIS) detector. HPLC was performed using a Venusil XBP C18 (5 $\mu \mathrm{m}, 250 \times$ $4.6 \mathrm{~mm}$ ) column eluted with a gradient mixture of acetonitrile in water containing $0.1 \%$ formic acid, from 5 to $95 \%$ in $60 \mathrm{~min}$.

\section{Determination of MIC and MBC}

The minimum inhibitory concentration (MIC) was determined using a 96-well microtiter plate and the microbroth dilution method as previously reported [20, 21]. Briefly, bacteria were seeded at $2 \times 10^{5}$ cells per well $(200 \mu \mathrm{L})$ in a 96 -well plate containing Mueller-Hinton (MH) broth $(0.2 \%$ meat extracts, $1.75 \%$ acid digest of casein, and $0.15 \%$ starch) with varying concentrations of each test sample. Vancomycin and berberine were used as positive controls. Dimethyl sulfoxide (DMSO; $10 \mu \mathrm{L}$ ) and $\mathrm{MH}$ broth alone were used as negative controls. The MIC was defined as the lowest concentration that completely prevented visible growth after incubation at $37^{\circ} \mathrm{C}$ for $18-20 \mathrm{~h}$. 
The minimum bactericidal concentration (MBC) was determined from tubes showing complete inhibition. A $\mathrm{MH}$ agar plate was seeded with $100-\mu \mathrm{L}$ aliquots from clear tubes and incubated for $24 \mathrm{~h}$ at $37^{\circ} \mathrm{C}$. The $\mathrm{MBC}$ was defined as the lowest compound concentration resulting in a $\geq 3-\log$ reduction in the number of CFU [22].

\section{Time-kill curves}

The time-kill kinetics of antimicrobial agent against $S$. aureus ATCC 29213 and ATCC 43300 were determined $[23,24]$. A logarithmic-phase broth culture of $S$. aureus was diluted in $\mathrm{MH}$ broth to a final count of approximately $5 \times 10^{5} \mathrm{CFU} / \mathrm{mL}$; next the antimicrobial agent was added to the broth culture to yield concentrations of $1 \times, 2 \times$, and $4 \times$ the MIC. An equivalent volume of DMSO was added to the vehicle control tube. The culture was incubated at $37{ }^{\circ} \mathrm{C}$ with shaking for $24 \mathrm{~h}$. Surviving clones in each culture were determined by withdrawing samples at various time points and plating the appropriate serial dilutions onto $\mathrm{MH}$ agar plates.

\section{Effect of $\mathrm{pH}$ and inoculum size}

The effect of changes in the $\mathrm{pH}$ of the medium and the inoculum size on the MIC of antimicrobial agent against S. aureus ATCC 29213 and ATCC 43300 were assessed [25]. The MIC was determined using the microbroth dilution method as described above. Inoculum size was remained constant in the $\mathrm{MH}$ broth $\left(1 \times 10^{5} \mathrm{CFU} / \mathrm{mL}\right)$ when the $\mathrm{pH}$ of the culture was adjusted to 5.0, 7.2, and 9.0 with either $\mathrm{HCl}$ or $\mathrm{NaOH}$. In contrast, the $\mathrm{pH}$ value of the $\mathrm{MH}$ broth remained at 7.2, while the inoculum size changed to $10^{3}, 10^{5}$, and $10^{7} \mathrm{CFU} / \mathrm{mL}$. To prevent interference from the high inoculum concentration on the MIC, the MBCs were used to confirm the MICs. All experiments were conducted in triplicate.

\section{Postantibiotic effect}

The Postantibiotic effect (PAE) of EF60 against $S$. aureus ATCC 29213 and ATCC 43300 was determined using $\mathrm{MH}$ broth. The sterilized antimicrobial agent was added to a logarithmic-phase broth culture of approximately $10^{5} \mathrm{CFU} / \mathrm{mL}$ to give concentrations equivalent to $1 \times$, $2 \times$, and $4 \times$ the MIC. In addition, a culture containing $5 \%$ DMSO was used as the growth control. Following $1 \mathrm{~h}$ of exposure at $37{ }^{\circ} \mathrm{C}$, the antibiotic concentration was reduced via a 1,000-fold dilution into prewarmed $\mathrm{MH}$ broth and incubated at $37{ }^{\circ} \mathrm{C}$ for $24 \mathrm{~h}$. Viable counts were measured on antibiotic-free $\mathrm{MH}$ broth prior to exposure and at $1,2,4,6,8$, and $24 \mathrm{~h}$ after neutralization by dilution. The PAE was then measured according to the method previously described [26].

\section{Cytotoxicity assay}

The cytotoxicity of EF60 against human red blood cells was assayed as previously described [27]. Human blood samples were obtained from normal volunteers. Hemolysis of red blood cells was induced by the addition of EF60, and cells were incubated for $2 \mathrm{~h}$ at $37{ }^{\circ} \mathrm{C}$ in $0.9 \%$ saline. The cytotoxicity of EF60 versus Human Umbilical Vein Endothelial Cells (HUVEC) was tested using a 48-h continuous 3-(4,5-dimethylthiazol-2-yl)2,5-diphenyltetrazolium bromide (MTT) assays as previously described [28].

\section{Statistical analysis}

Statistical analyses were performed using SPSS software (Statistical Software Package for Windows, version 19). The PAEs were expressed as the mean \pm standard deviation, and differences are considered to be statistically significant at $P<0.05$.

\section{Results \\ Isolation of phenanthrene fractions from the fibrous roots of $B$. striata}

To obtain phenanthrene fractions, ethanol extract from the fibrous roots of $B$. striata was loaded onto a polyamide resin column and eluted using step-gradient ethanol in water to generate five fractions, namely EF20, EF40, EF60, EF80, and EF95. Phenanthrenes were analyzed by analytical HPLC and identified by congruent retention times and UV-VIS spectrum, and EF60 was found to be rich in phenanthrenes (Additional file 1: Figure S1, Table S1, and Figure S2). Further study indicated that EF60 had good activity against S. aureus (Table 1). Thus, in the current work, subsequent efforts were focused on the characterization of this active fraction. EF60 was produced as described in the Methods section with a yield of $14.9 \mathrm{~g}$ per $1 \mathrm{~kg}$ of fibrous root.

\section{Antibacterial activity of EF60}

The antimicrobial activities of EF60 were evaluated against 16 Gram-positive and 2 Gram-negative bacteria strains. As expected, EF60 was active against all the Gram-positive bacteria, with the MICs ranging from 8 to $64 \mu \mathrm{g} / \mathrm{mL}$ (Table 2). However, EF60 was not active against each of the Gram-negative bacteria (MIC >128 $\mu \mathrm{g} / \mathrm{mL}$ ). Although berberine, a famous natural product from Chinese herbs, had antimicrobial activity against both Gram-positive and Gram-negative bacteria [29], its MIC against most of the strains examined was found to be $>64 \mu \mathrm{g} / \mathrm{mL}$ (Table 2). It is worth noting that clinical isolates of $S$. aureus and MRSA ATCC 43300 were also sensitive to EF60.

To evaluate the bactericidal behavior of EF60, the MBC was determined for the three standard strains and the two clinical isolates of $S$. aureus. The control agent, vancomycin, yielded $\mathrm{MBC} / \mathrm{MIC}$ ratios of 1-2 against all of 
Table 1 Antimicrobial activity of different polyamide resin elution fractions from Bletilla striata fibrous root ethanol extract

\begin{tabular}{|c|c|c|c|c|c|c|}
\hline \multirow[t]{2}{*}{ Indicator strain } & \multicolumn{6}{|c|}{ Inhibition zone size (mm diameter) } \\
\hline & $\mathrm{EF} 20^{\mathrm{a}}$ & $\mathrm{EF} 40^{\mathrm{a}}$ & $\mathrm{EF} 60^{\mathrm{a}}$ & $\mathrm{EF} 80^{\mathrm{a}}$ & $\mathrm{EF95}^{\mathrm{a}}$ & $A m p^{b}$ \\
\hline Staphylococcus aureus ATCC 25923 & NA & $12 \pm 0.4$ & $21 \pm 0.7$ & NA & NA & $27 \pm 0.6$ \\
\hline Escherichia coli ATCC 35218 & NA & NA & NA & NA & NA & $20 \pm 0.3$ \\
\hline
\end{tabular}

${ }^{a}$ Relative inhibition zone $(\mathrm{mm})$ at $100 \mu \mathrm{g}$ per paper disc

${ }^{b}$ Relative inhibition zone $(\mathrm{mm})$ at $10 \mu \mathrm{g}$ per paper disc

Amp ampicillin

$N A$ no activity

the strains tested (Table 3), indicative of bactericidal antistaphylococcal behavior. Interestingly, EF60 exhibited MBC/MIC ratios of 1-2 against ATCC 21923 and clinical isolate 3304, but it yielded $\mathrm{MBC} / \mathrm{MIC}$ ratios $>8$ against ATCC 25923, ATCC 43300, and clinical isolate 3211 (Table 3). In accordance with the standards of the Clinical and Laboratory Standards Institute [30], an MBC/MIC ratio of 1-2 is indicative of bactericidal behavior, while a corresponding $\mathrm{MBC} / \mathrm{MIC}$ ratio $\geq 8$ is indicative of bacteriostatic behavior. Thus, EF60 is bactericidal against $S$. aureus 3304 and ATCC 29213 and bacteriostatic against S. aureus 3211, ATCC 25923, and ATCC 43300. Similarly, berberine was bacteriostatic against $S$. aureus ATCC 25923 and ATCC 29213 and bactericidal against S. aureus 3211, 3304, and ATCC 43300.

Table 2 MIC of EF60 against standard strains and clinical isolates

\begin{tabular}{llll}
\hline Indicator strain & \multicolumn{3}{l}{ MIC $(\mu \mathrm{g} / \mathrm{mL})^{\mathrm{a}}$} \\
\cline { 2 - 4 } & $\mathrm{EF} 60$ & Berberine & Vancomycin \\
\hline S. aureus ATCC 25923 & 32 & 128 & 2 \\
S. aureus ATCC 29213 & 16 & 64 & 1 \\
S. aureus ATCC 43300 & 8 & 128 & 2 \\
S. aureus 5021 & 64 & 64 & 1 \\
S. aureus 5022 & 16 & 64 & 1 \\
S. aureus 5023 & 32 & 128 & 1 \\
S. aureus 5024 & 64 & 256 & 2 \\
S. aureus 5025 & 16 & 128 & 1 \\
S. aureus 5026 & 16 & 256 & 1 \\
S. aureus 5027 & 16 & 64 & 1 \\
S. aureus 5028 & 16 & 64 & 1 \\
S. aureus 5029 & 16 & 64 & 1 \\
S. aureus 3211 & 8 & 128 & 1 \\
S. aureus 3304 & 16 & 128 & 1 \\
S. aureus 2798 & 8 & 128 & 1 \\
Bacillus subtilis 168 & 32 & 128 & 0.25 \\
Escherichia coli ATCC 35218 & $>128$ & 128 & - \\
Pseudomonas aeruginosa ATCC 27853 & $>128$ & 256 & - \\
\hline MIC minimum inhbitory concentato & & &
\end{tabular}

MIC minimum inhibitory concentration

a_, not determined
To further examine the bactericidal/bacteriostatic activities of EF60 against $S$. aureus with regard to $\mathrm{MBC} / \mathrm{MIC}$ ratios, killing experiments against ATCC 29213 and 43300 were performed. As shown in Fig. 1, EF60 produced $>3$ logs of kill against ATCC 29213 at concentrations of $\geq 2 \times$ the MIC. However, less than 2 logarithmic units of killing were observed, even at $4 \times$ the MIC of EF60, against ATCC 43300. This observation is consistent with the bactericidal/bacteriostatic behavior revealed by the $\mathrm{MBC} / \mathrm{MIC}$ analysis described above. It is worth mentioning that at concentrations of $\geq 2 \times$ the MIC, the killing kinetics of EF60 against ATCC 29213 are faster than those of vancomycin.

Table 3 The MBC of EF60 against standard strains and clinical isolates

\begin{tabular}{|c|c|c|c|}
\hline Strain and compound & MIC $(\mu \mathrm{g} / \mathrm{mL})$ & $\mathrm{MBC}(\mu \mathrm{g} / \mathrm{mL})$ & $\mathrm{MBC} / \mathrm{MIC}$ \\
\hline \multicolumn{4}{|l|}{ S. aureus ATCC 25923} \\
\hline EF60 & 32 & $>256$ & $>8$ \\
\hline Berberine & 128 & $>512$ & $>4$ \\
\hline Vancomycin & 2 & 2 & 1 \\
\hline \multicolumn{4}{|l|}{ S. aureus ATCC 29213} \\
\hline EF60 & 16 & 32 & 2 \\
\hline Berberine & 64 & $>512$ & $>8$ \\
\hline Vancomycin & 1 & 2 & 2 \\
\hline \multicolumn{4}{|l|}{ S. aureus ATCC 43300} \\
\hline EF60 & 8 & $>128$ & $>8$ \\
\hline Berberine & 128 & 128 & 1 \\
\hline Vancomycin & 2 & 2 & 1 \\
\hline \multicolumn{4}{|l|}{ S. aureus 3211} \\
\hline EF60 & 8 & $>128$ & $>16$ \\
\hline Berberine & 128 & 256 & 2 \\
\hline Vancomycin & 1 & 2 & 2 \\
\hline \multicolumn{4}{|l|}{ S. aureus 3304} \\
\hline EF60 & 16 & 32 & 2 \\
\hline Berberine & 128 & 128 & 1 \\
\hline Vancomycin & 1 & 1 & 1 \\
\hline
\end{tabular}

MIC minimum inhibitory concentration

$M B C$ minimum bactericidal concentration 
S. aureus ATCC 29213

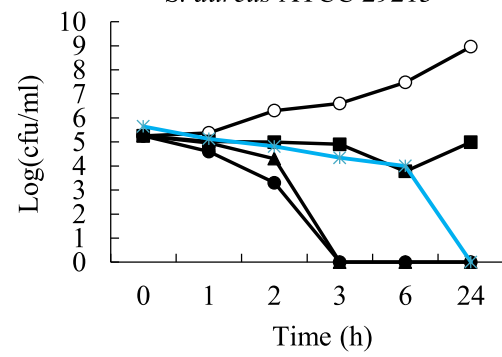

S. aureus ATCC 43300

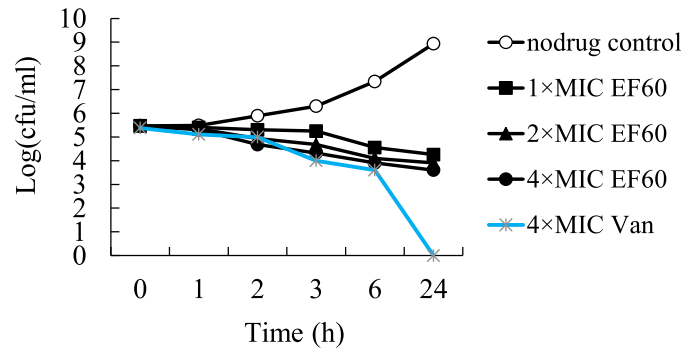

Fig. 1 Time-kill curves for Staphylococcus aureus ATCC 29213 and 43300. Each data point reflects the average of two independent measurements. The curves are viable cell concentrations plotted against time. Open circles, nondrug control; closed squares, 1× MIC of EF60; closed triangles, 2X MIC of EF60; closed circles, 4X MIC of EF60; asterisk, 4× MIC of vancomycin. MIC, minimum inhibitory concentration

\section{Effect of $\mathrm{pH}$ and inoculum size on MICs of EF60}

Table 4 summarized the MICs for the two strains of $S$. aureus obtained at different $\mathrm{pH}$ and inoculum concentrations. There was only a twofold increase in the MICs of EF60 for ATCC 29213 and 43300, from 16 and $8 \mu \mathrm{g} /$ $\mathrm{mL}$ at $\mathrm{pH} 5$ to 32 and $16 \mu \mathrm{g} / \mathrm{mL}$ at $\mathrm{pH}$ 9, respectively. Similar reduction potency was observed when the inoculum sizes changed from $10^{3}$ to $10^{7} \mathrm{CFU} / \mathrm{mL}$. Generally, both the $\mathrm{pH}$ and inoculum sizes did not significantly affect the MICs of EF60 against the two strains of S. aureus under the tested conditions.

\section{Postantibiotic effect}

The PAE of EF60 on the reference strains was determined and is shown in Table 5. A PAE of $>1.5 \mathrm{~h}$ was observed on strain ATCC 29213 for all tested concentrations of EF60, compared with the maximum PAE of $0.38 \mathrm{~h}$ for strain 43300 after exposure to $64 \mu \mathrm{g} / \mathrm{mL}$ of EF60. Although the PAE of EF60 increased with increasing concentrations of the drug, the dose-dependent PAE on S. aureus from 1 to $4 \times$ the MIC of EF60 was not significant $(P>0.05)$.

\section{Cytotoxicity}

The cytotoxicity of EF60 against mammalian cells was tested by hemolysis and MTT assays. No hemolytic

Table 4 The effect of changes in the $\mathrm{pH}$ medium and the inoculum size on EF60 activity

\begin{tabular}{llll}
\hline Influence factor & & MIC $(\mu \mathrm{g} / \mathrm{mL})$ & \\
\cline { 2 - 4 } & & S. aureus ATCC 29213 & S. aureus ATCC 43300 \\
\hline pH of medium & 5 & 16 & 8 \\
& 7 & 16 & 8 \\
& 9 & 32 & 16 \\
Inoculum size & $10^{3}$ & 16 & 8 \\
(CFU/mL) & $10^{5}$ & 16 & 8 \\
& $10^{7}$ & 32 & 16 \\
\hline
\end{tabular}

MIC minimum inhibitory concentration activity was observed against human erythrocytes when the concentration of EF60 reached $160 \mu \mathrm{g} / \mathrm{mL}$. At this concentration, EF60 effectively inhibited the growth of all of the Gram-positive bacteria tested, including MRSA. However, EF60 was minimally toxic to HUVEC, with an $\mathrm{IC}_{50}$ of $75 \mu \mathrm{g} / \mathrm{mL}$, indicating a different cytotoxicity against cell lines derived from diverse tissues. Future studies with additional human cell lines will be done to evaluate the toxicity of EF60.

\section{Discussion}

In this study, a plant fraction (EF60) from the ethanol extract of fibrous roots of B. striata pseudobulbs was isolated and characterized. EF60 was eluted from a polyamide resin column with $60 \%$ ethanol and found to be rich in phenanthrenes. Antimicrobial activity tests demonstrated that EF60 had good activity against Gram-positive bacteria, including $S$. aureus clinical isolates and MRSA. Interestingly, the MICs of EF60 against all tested S. aureus strains were $8-64 \mu \mathrm{g} / \mathrm{mL}$ and lower than those of berberine (Table 2), which is a famous natural antibiotic in China. On the basis of the MIC values, which are below $100 \mu \mathrm{g} / \mathrm{mL}$ for the fraction against Gram-positive bacteria, EF60 is regarded as a significantly active antibacterial agent and deserve our full attention [31, 32].

Many antibiotics used in clinical, such as penicillin, vancomycin, and daptomycin, exhibit fast and bactericidal effects. Some, such as erythromycin and tigecycline, however, are bacteriostatic rather than bactericidal. To evaluate the bactericidal behavior of EF60, the MBC

Table 5 PAE of EF60 against Staphylococcus aureus strains ${ }^{a}$

\begin{tabular}{lcc}
\hline Drug concentration & PAE $(\mathrm{h})$ mean \pm SD & \\
\cline { 2 - 3 } in $\mu \mathrm{g} / \mathrm{mL}$ & S. aureus ATCC 29213 & S. aureus ATCC 43300 \\
\hline $16(1 \times \mathrm{MIC})$ & $1.53 \pm 0.08$ & $0.28 \pm 0.04$ \\
$32(2 \times \mathrm{MIC})$ & $1.87 \pm 0.02$ & $0.30 \pm 0.06$ \\
$64(4 \times \mathrm{MIC})$ & $2.00 \pm 0.05$ & $0.38 \pm 0.06$
\end{tabular}

${ }^{a}$ Approximately $10^{5} \mathrm{CFU} / \mathrm{mL}$ was exposed to different concentrations of EF60 for $1 \mathrm{~h}$ 
was determined for five $S$. aureus strains. As shown in Table 3, against 3 of these strains EF60 showed only bacteriostatic activities. With the other 2 strains, bactericidal activities of EF60 were observed. Similar phenomena were also observed for berberine and in other studies [33]. The bactericidal/bacteriostatic behavior of EF60 was confirmed by time-kill assays (Fig. 1).

It was reported that the $\mathrm{pH}$ of culture medium or inoculum size had an effect on the antibacterial activities of some antibiotics [25, 31]. For example, amifloxacin was more active against Staphylococcus saprophyticus at pH 6.0 than at 7.0 [25], while the oil of Cedrus deudora had most active at $\mathrm{pH} 9$ [31]. In the present study, variations in the $\mathrm{pH}$ of the medium or inoculum density had no significant effect on the activity of EF60 (Table 4), indicated this plant fraction had a high stability when susceptibility test conditions were modified.

PAE is the phenomenon of suppression of bacterial growth after a short exposure to antimicrobial agents $[26,34]$. It is an important parameter of antibiotic action, and provides reference data for designing antibiotic dosage regimens. Previous studies indicated that many test antibiotics had a persistent inhibition of bacterial growth after a brief antimicrobial exposure to microorganisms [35-37], while some drugs had insignificant PAE [34]. Our study showed that the PAE was related with both the concentration of EF60 and test strains: for example, the PAEs for Strain ATCC 29213 were $1.53 \mathrm{~h}$ after exposure to $16 \mu \mathrm{g} / \mathrm{mL}$ and $2.0 \mathrm{~h}$ after exposure to $64 \mu \mathrm{g} / \mathrm{mL}$, but the PAE for Strain ATCC 43300 was $0.38 \mathrm{~h}$ after exposure to $64 \mu \mathrm{g} / \mathrm{mL}$ (Table 5 ).

Herbal drugs are often claimed to be nontoxic or low toxic, but this is not always the case, especially for certain plant extracts and phytochemicals [32]. It is important to measure the toxicity of new antimicrobial agents to cell lines and animals. The in vitro cytotoxicity assay indicated that EF60 was minimally toxic to HUVEC with an $\mathrm{IC}_{50}$ of $75 \mu \mathrm{g} / \mathrm{mL}$. More studies with additional human cell lines and animals should be done to evaluate the toxicity of EF60.

\section{Conclusion}

In conclusion, EF60, a plant fraction rich in phenanthrenes, has a potent activity against Gram-positive bacteria, including MRSA and S. aureus clinical isolates, which represents the most frequent cause of complicated skin and soft tissue infections worldwide [38]. This antimicrobial activity of EF60 seems to have a direct correlation to the traditional use of the herb for curing skin cracks and abscesses. Our study revealed that EF60 may be applied to the development of natural antibacterial products. However, more studies on the in vivo antimicrobial activity, bioavailability, and mechanism of action of EF60 are needed to be conducted.

\section{Additional file}

Additional file 1: Figure S1. HPLC analysis of standard sample and EF60. Table S1. The retention times of standard samples and compounds of EF60. Figure S2. UV spectrum of standard samples and compounds $1-8$ of EF60. (DOCX $427 \mathrm{~kb}$ )

\section{Abbreviations}

DMSO: Dimethyl sulfoxide; HPLC: High-pressure liquid chromatography; HUVEC: Human umbilical vein endothelial cells; MBC: Minimum bactericidal concentration; MIC: Minimum inhibitory concentration; MRSA: Methicillinresistant Staphylococcus aureus; MTT: 3-(4,5-dimethylthiazol-2-yl)-2,5diphenyltetrazolium bromide; PAE: Postantibiotic effect; VAN: Vancomycin

\section{Acknowledgment}

We thank for Mei-Ya Li of Zhejiang Chinese Medical University for providing Bacillus subtilis 168.

\section{Funding}

This work was supported by Zhejiang Provincial Public Welfare Technology Research and Social Development Project of China (2016C33087), National natural science foundation of China (81503329), and Zhejiang Provincial Natural Science Foundation of China (LY16H310005).

\section{Availability of data and materials}

The datasets supporting the conclusions of this article are presented in this main paper and additional file.

\section{Authors' contributions}

JJG carried out the assays of antibacterial activity. BLD and NPC carried out the isolation of EF60. LXJ and FSJ helped to revise the manuscript. ZSD and CDQ were responsible for designing the study. CDQ wrote the manuscript. All authors read and approved the final manuscript.

\section{Competing interests}

The authors declare that they have no competing interests.

\section{Consent for publication}

Not applicable.

\section{Ethics approval and consent to participate}

Authorization for the collection of blood was obtained from the Medical and Ethical Committee of Zhejiang Hospital of Traditional Chinese Medicine. An informed consent for the use of their blood in this study was obtained from the donors.

\section{Author details}

'Zhejiang Chinese Medical University, Hangzhou, Zhejiang Province, China.

${ }^{2}$ Shaoxing Central Hospital, Shaoxing, Zhejiang Province, China.

Received: 2 August 2016 Accepted: 25 November 2016

Published online: 29 November 2016

References

1. Nathan C, Cars O. Antibiotic resistance-problems, progress, and prospects. New Engl J Med. 2014;371:1761-3.

2. Spellberg B, Bartlett J, Wunderink R, Gilbert DN. Novel approaches are needed to develop tomorrow's antibacterial therapies. Am J Resp Crit Care Med. 2015;191(2):135-40.

3. Michael GB, Freitag C, Wendlandt S, Eidam C, Feßler AT, Lopes GV, et al. Emerging issues in antimicrobial resistance of bacteria from food-producing animals. Future Microbiol. 2015;10:427-43.

4. Mediavilla JR, Chen L, Mathema B, Kreiswirth BN. Global epidemiology of community- associated methicillin resistant Staphylococcus aureus (CA-MRSA). Curr Opin Microbiol. 2012;15:588-95.

5. Fridkin SK, Hageman JC, Morrison M, Sanza LT, Como-Sabetti K, Jernigan JA, et al. Methicillin-resistant Staphylococcus aureus disease in three communities. N Engl J Med. 2005;352:1436-44.

6. Johnson AP, Uttley AH, Woodford N, George RC. Resistance to vancomycin and teicoplanin: an emerging clinical problem. Clin Microbiol Rev. 1990;3:280-91. 
7. Kahne D, Leimkuhler C, Lu W, Walsh C. Glycopeptide and lipoglycopeptide antibiotics. Chem Rev. 2005;105:425-48.

8. Butler MS, Hansford KA, Blaskovich MA, Halai R, Cooper MA. Glycopeptide antibiotics: back to the future. J Antibiot (Tokyo). 2014;67(9):631-44.

9. Dorman HJD, Deans SG. Antimicrobial agents from plants: antibacterial activity of plant volatile oils. J Appl Microbiol. 2000:88:308-16.

10. Simoes M, Bennett RN, Rosa EA. Understanding antimicrobial activities of phytochemicals against multidrug resistant bacteria and biofilms. Nat Prod Rep. 2009;26(6):746-57.

11. Sun LL, Yang YH, Liu JK, Cheng WF, Zhou M. Studies on botanical origin of Bletilla striata and its textual research herb textual research. J Chinese Med Mater. 2010;33(12):1965-8.

12. Takagi S, Yamaki M, Inoue K. Antimicrobial agents from Bletilla striata. Phytochemistry. 1983;22:1011-5.

13. Yamaki M, Bai L, Inoue K, Takagi S. Biphenanthrenes from Bletilla striata, Phytochemistry, 1989; 28:(12):3503-3350.

14. Kovács A, Vasas A, Hohmann J. Natural phenanthrenes and their biological activity. Phytochemistry. 2008;69:1084-110.

15. Jiang F, Li W, Huang Y. Antioxidant, antityrosinase and antitumor activity comparison: the potential utilization of fibrous root part of Bletilla striata (Thunb.) Reichb.f. PLoS One. 2013;8(2):e58004.

16. Qian CD, Jiang FS, Yu HS, Shen Y, Fu YH, Cheng DQ, et al. Antibacterial Biphenanthrenes from the fibrous roots of Bletilla striata. J Nat Prod. 2015; 78(4):939-43.

17. Sun A, Liu J, Pang S, Lin J, Xu R. Two novel phenanthraquinones with anti-cancer activity isolated from Bletilla striata. Bioorg Med Chem Let. 2016;26(9):2375-9.

18. Xiao $S, X u$ D, Zhang M, Lin H, Ding L, Zhou S, Zhou Y. A novel phenanthrene1,2-dione from Bletilla striata. Chinese J Org Chem. 2016;36(3):638-41.

19. Teng Y, Zhao WP, Qian CD, Li O, Zhu L, Wu XC. Gene cluster analysis for the biosynthesis of elgicins, novel lantibiotics produced by Paenibacillus elgii B69. BMC Microbiol. 2012;12:45

20. Romero-Tabarez M, Jansen R, Sylla M, Lunsdorf H, Haussler S, Santosa DA, et al. 7-O-malonyl macrolactin $\mathrm{A}$, a new macrolactin antibiotic from Bacillus subtilis active against methicillin-resistant Staphylococcus aureus, vancomycin-resistant enterococci, and a smallcolony variant of Burkholderia cepacia. Antimicrob Agents Chemother. 2006;50:1701-9.

21. Wu XC, Qian CD, Fang HH, Wen YP, Zhou JY, Zhan ZJ, et al. Paenimacrolidin, a novel macrolide antibiotic from Paenibacillus sp. F6-B70 active against methicillinresistant Staphylococcus aureus. Microb Biotechnol. 2011;4(4):491-502.

22. Kaul M, Mark L, Zhang Y, Parhi AK, LaVoie EJ, Pilch DS. An FtsZ-targeting prodrug with oral antistaphylococcal efficacy in vivo. Antimicrob Agents Chemother. 2013;57:5860-9.

23. Qian CD, Wu XC, Teng Y, Zhao WP, Li O, Fang SG, et al. Battacin (octapeptin B5), a new cyclic lipopeptide antibiotic from Paenibacillus tianmuensis active against multidrug-resistant gram-negative bacteria. Antimicrob Agents Chemother. 2012;56(3):1458-65.

24. Huang ZH, Hu Y, Shou LF, Song MX. Isolation and partial characterization of cyclic lipopeptide antibiotics produced by Paenibacillus ehimensis B7. BMC Microbiol. 2013;13:87.

25. Iravani A, Welty GS, Newton BR, Richard GA. Effects of changes in pH, medium, and inoculum size on the in vitro activity of amifloxacin against urinary isolates of Staphylococcus saprophyticus and Escherichia coli. Antimicrob Agents Chemother. 1985;27(4):449-51.

26. Boswell FJ, Andrews JM, Wise R. Postantibiotic effect of trovafloxacin on Pseudomonas aeruginosa. J Antimicrob Chemother. 1997;39:811-4.

27. Kondejewski LH, Farmer SW, Wishart DS, Hancock REW, Hodges RS. Gramicidin $\mathrm{S}$ is active against both gram-positive and gram-negative bacteria. Int J Pept Protein Res. 1996;47:460-6.

28. Boncler M, Różalski M, Krajewska U, Podsędek A, Watala C. Comparison of prestoblue and mtt assays of cellular viability in the assessment of antiproliferative effects of plant extracts on human endothelial cells. J Pharmacol Toxicol Methods. 2014;69(1):9-16.

29. Domadia PN, Bhunia A, Sivaraman J, Swarup S, Dasqupta D. Berberine targets assembly of Escherichia coli cell division protein FtsZ. Biochemistry. 2008:47:3225-34

30. CLSI. Methods for dilution antimicrobial susceptibility tests for bacteria that grow aerobically; approved standard, Document M07-A8. 8th ed. Wayne: Clinical and Laboratory Standards Institute; 2009.

31. Rios J, Recio M. Medicinal plants and antimicrobial activity. J Ethnopharmacol. 2005;100:80-4.
32. Radulovic NS, Blagojevic PD, Stojanovic-Radic ZZ, Stojanovic NM. Antimicrobial plant metabolites: structural diversity and mechanism of action. Curr Med Chem. 2013;20(7):932-52.

33. Djeussi DE, Noumedem JAK, Ngadjui BT, Kuete V. Antibacterial and antibiaoticmodulation activity of six Cameroonian medicinal plants against Gran-negative multi-drug resistant phenotypes. Bmc Compem Altern. 2016;16:124.

34. Xue IC, Davey PG, Phillips G. Variation in postantibiotic effect of clindamycin against clinical isolates of Staphylococcus aureus and implications for dosing of patients with osteomyelitis. Antimicrob Agents Chemother. 1996;40(6):1403-7.

35. Pillar CM, Stoneburner A, Shinabarger DL, Krause KM, Nichols WW. The postantibiotic effect and post-beta-lactamase-inhibitor effect of ceftazidime, ceftaroline and aztreonam in combination with avibactam against target gram-negative bacteria. Lett Appl Microbiol. 2016;63(2):96-102.

36. Giguere S, Lee EA, Guldbech KM, Berghaus LJ. In vitro synergy, pharmacodynamics, and postantibiotic effect of 11 antimicrobial agents against Rhodococcus equi. Vet Microbiol. 2012;160(1-2):207-13.

37. Babakhani F, Gomez A, Robert N, Sears P. Postantibiotic effect of fidaxomicin and its major metabolite, OP-1118, against Clostridium difficile. Antimicrob Agents Chemother. 2011;55(9):4427-9.

38. Bassetti M, Righi E, Carnelutti A. New therapeutic options for skin and soft tissue infections. Curr Opin Infect Dis. 2016;29(2):99-108.

\section{Submit your next manuscript to BioMed Central and we will help you at every step:}

- We accept pre-submission inquiries

- Our selector tool helps you to find the most relevant journal

- We provide round the clock customer support

- Convenient online submission

- Thorough peer review

- Inclusion in PubMed and all major indexing services

- Maximum visibility for your research

Submit your manuscript at www.biomedcentral.com/submit
Biomed Central 